\title{
Relationship between Coronal Alignment and Posterior Tibial Slope in the Lower Extremity
}

\author{
Serhat Mutlu1 ${ }^{*}$, Harun Mutlu², Olcay Guler ${ }^{3}$, Gokhan Ozkazanli², Atilla Parmaksizoglu2 \\ ${ }^{1}$ Department of Orthopaedics and Traumatology, Kanuni Sultan Suleyman Education and Research Hospital, \\ Istanbul, Turkey \\ ${ }^{2}$ Department of Orthopaedics and Traumatology, Taksim Education and Research Hospital, Istanbul, Turkey \\ ${ }^{3}$ Department of Orthopaedics and Traumatology, Medipol University Medical School, Istanbul, Turkey \\ Email: ${ }^{\text {drserhatmutlu@yahoo.com }}$
}

Received 22 February 2014; revised 26 March 2014; accepted 3 April 2014

Copyright (C) 2014 by authors and Scientific Research Publishing Inc.

This work is licensed under the Creative Commons Attribution International License (CC BY).

http://creativecommons.org/licenses/by/4.0/

(c) (i) Open Access

\begin{abstract}
Purpose: To restore the normal axial alignment of the lower extremity is important in reconstructive knee surgery. The aim of this study was to evaluate lower-limb alignment and posterior tibial slope. Methods: Thirty-two male and 32 female outpatients aged 22 to 46 were recruited. A full weight-bearing anteroposterior radiograph of the entire lower limb was obtained for each subject. The axial alignment was measured based on the centers of the femoral head, knee, and ankle. The tibiofemoral (TF), tibial joint (TJ), and posterior tibial slope (TS) angles were determined. Results: The mean TF angle was more varus in women $\left(177.8^{\circ}\right)$ than men $\left(179.2^{\circ}\right)$, and the mean $\mathrm{TJ}$ angle was more medially inclined in women than men. Women had a greater $\mathrm{TJ}$ angle than men $\left(93.3^{\circ} \mathrm{vs}\right.$. $\left.91.6^{\circ}\right)$. The mean posterior TS was greater in men than women $\left(16.0^{\circ}\right.$ vs. $\left.12.5^{\circ}, \mathrm{p}<0.05\right)$, while the mean TS angle was greater in women $\left(14.8^{\circ}\right)$ than men $\left(12.3^{\circ}\right)$. Conclusion: Knee alignment and geometry vary among populations. In our study, the TF angle was varus among all participants. The knee joint was more medially inclined in women than men. And also the posterior TS was greater in women than men.
\end{abstract}

\section{Keywords}

Knee Joint, Alignment, Posterior Tibial Slope

\footnotetext{
${ }^{*}$ Corresponding author.
}

How to cite this paper: Mutlu, S., Mutlu, H., Guler, O., Ozkazanli, G. and Parmaksizoglu, A. (2014) Relationship between Coronal Alignment and Posterior Tibial Slope in the Lower Extremity. Open Journal of Orthopedics, 4, 97-100. 


\section{Introduction}

Restoration of the neutral mechanical alignment of the lower limb in the coronal plane and the correct rotational alignment in the axial plane are considered as two of the most important issues in knee surgery such as total knee arthroplasty and high tibial osteotomy. The importance of restoring the alignment of the lower extremity after total knee arthroplasty has been emphasized [1], while radiographic variation in the normal lower extremity alignments of different population subsets has been reported [2] [3]. A total knee replacement with varus alignment has been shown to fail substantially earlier than those with neutral or valgus alignment (Ritter). The normal alignment of the lower extremity has not been documented clearly in Turkish adults. We evaluated the posterior tibial slope (TS) and lower extremity alignment of 64 outpatients.

\section{Materials and Methods}

Between January 2012 and October 2013, 32 male and 32 female outpatients aged 22 to 46 who had slight pain in their knees were recruited. In all subjects, no osseo-ligamentous pathology was found and the pain was spontaneously interrupted. Our exclusion criteria were a history of trauma, deformity, or surgery of the hip, ankle, or knee joints. Ethics approval was taken for this study. A full weight-bearing anteroposterior radiograph of the lower extremity was taken for each subject by Samsung X-Ray Machine XGEO GU60. The coronal alignment of the extremity was measured based on the centers of the femoral head, knee, and ankle (Figure 1). We measured all measurements by using infinity software digitally. The mechanical axes of the femur and the tibia were the lines between the centers of the femoral head and knee and the centers of the knee and ankle. The medial angle formed by the mechanical axes of the femur and tibia was the tibiofemoral (TF) angle, which measured the overall alignment of the lower limb. A TF angle of $<180^{\circ}$ indicated varus alignment. The tibial joint angle (TJ) was the inferolateral angle formed by the transverse axis of the knee and the mechanical axis of the tibia. A TJ angle of $>90^{\circ}$ indicated medial inclination of the knee joint.

On the lateral radiograph of the knee, the posterior TS was determined by the medial tibial plateau, lateral tibial plateau, and anterior tibial cortex line. The posterior TS was calculated by subtracting from $90^{\circ}$ the angle formed by the tibial plateau and the anterior tibial cortex line (Figure 2).

The five authors made all the measurements together. Thus there was no conflict between the authors. The variables were compared with a paired t-test.

\section{Results}

The mean TF angle for all participants was $178.8^{\circ}\left(175.2^{\circ}-184.4^{\circ}\right)$. For men and women, the mean TF angles were $177.8^{\circ}\left(175.2^{\circ}-182.3^{\circ}\right)$ and $179.2^{\circ}\left(177.1^{\circ}-184.4^{\circ}\right)$, respectively. Women had a statistically significant more varus mean TF than men $(\mathrm{p}<0.05)$.

The mean TJ angle for all participants was $92.3^{\circ}\left(89.3^{\circ}-94.2^{\circ}\right)$. Women had a mean TJ angle of $93.3^{\circ}\left(90.2^{\circ}-\right.$ $\left.94.2^{\circ}\right)$ and men of $91.6^{\circ}\left(89.3^{\circ}-93.6^{\circ}\right)$. The mean TJ angle was found to be statistically significantly more medially inclined in women than men $(\mathrm{p}<0.05)$.

For all participants, the mean angle of the posterior TS was $13.6^{\circ}\left(11.2^{\circ}-15.3^{\circ}\right)$. The mean TS for women and men was $14.8^{\circ}\left(12.8^{\circ}-15.3^{\circ}\right)$ and $12.3^{\circ}\left(11.2^{\circ}-14^{\circ}\right)$, respectively. Women had a statistically significant higher mean TS angle than men $(\mathrm{p}<0.05)$. The results were shown in Table 1.

\section{Discussion}

Normal lower extremity alignments and geometry vary among different population subsets [2] [4] [5]. The normal alignment of the lower extremity has not been documented clearly before in Turkish adults. We evaluated the lower extremity alignment and the posterior tibial slope of 64 subjects. The TF angle was varus among all participants. These findings could be helpful for the orthopaedic surgeons. As we know, total knee replacement with varus alignment has been shown to fail substantially earlier than those with neutral or valgus alignment [6]. Likewise, both Hsu et al. [2] and Tang et al. [3] reported varus alignment in men and women. Khattak et al. [7] observed more varus alignment in Pakistani men than women. Our results were similar to those of Tang et al. [3] who found greater varus alignment in Chinese women than men.

Varus alignment might be a contributing factor for osteoarthritis [8], and the TJ angle is an index of the obliquity of the knee joint. Hsu et al. [2] and Tang et al. [3] reported that women have a greater TJ angle than men, 


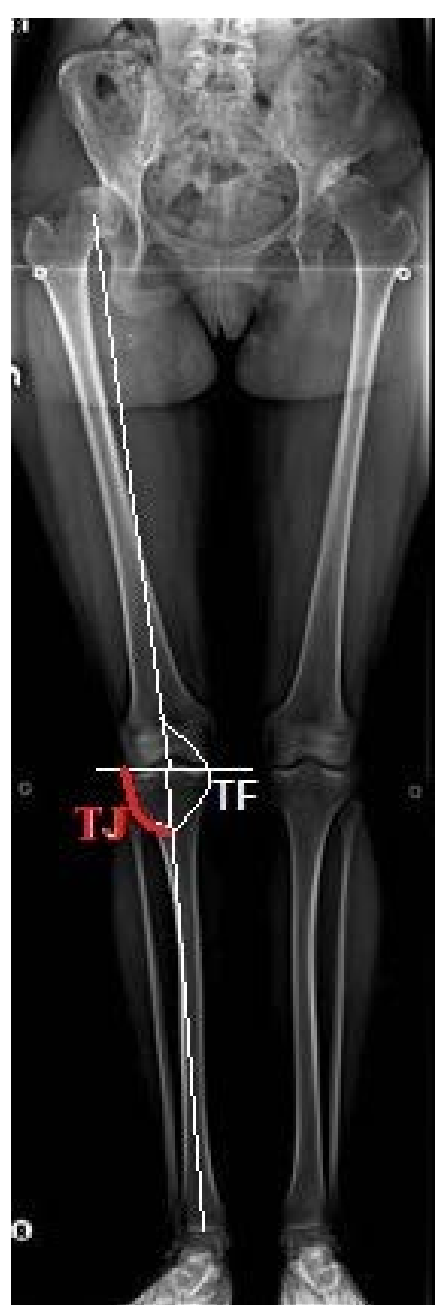

Figure 1. A full weight-bearing anteroposterior radiograph of the lower extremity. TJ: Tibial Joint Angle. TF: Tibiofemoral Angle.

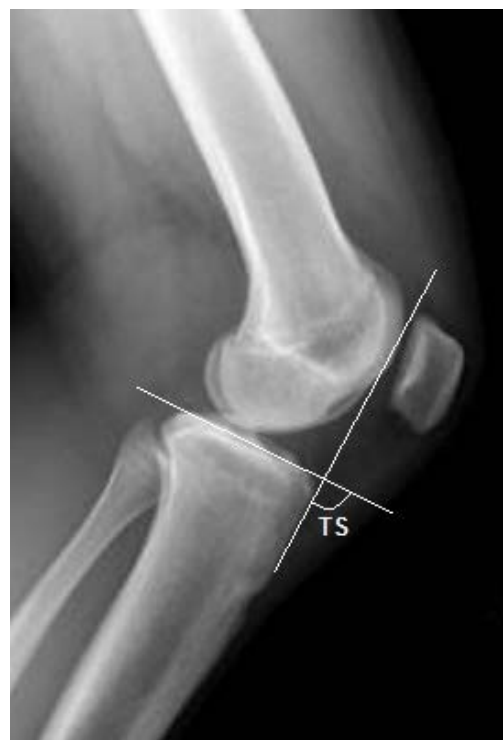

Figure 2. A lateral radiograph of the knee. TS: Tibial Slope Angle. 
Table 1. Comparison of the angles between the women and the men.

\begin{tabular}{cccc}
\hline & Women & Men & P \\
\hline TF (degree) & $179.2^{\circ}$ & $177.8^{\circ}$ & $<0.05$ \\
TJ (degree) & $93.3^{\circ}$ & $91.6^{\circ}$ & $<0.05$ \\
TS (degree) & $14.8^{\circ}$ & $12.3^{\circ}$ & $<0.05$ \\
\hline
\end{tabular}

TF: The mean tibiofemoral angle. TJ: The mean tibial joint angle. TS: The mean angle of the posterior tibial slope

but Khattak et al. [7] found the opposite. In our study, the knee joint was more medially inclined in women than men.

The posterior TS is important for flexion stability and range of motion. Its effects on the subsidence or loosening of the tibial component and the postoperative range of motion and knee kinematics have been reported [9]-[11]. Too great a posterior TS exposes weak, cancellous bone posteriorly. In our study, the posterior TS was greater in women than men. These results were similar with those found in the study by Khattak et al. [7]. Further studies with a larger cohort may be helpful for the results of the knee surgeries.

\section{Conclusion}

In Turkish adults, we found that the TF angle was varus among all participants. The knee joint was more medially inclined in women than men. And also the posterior TS was greater in women than men. This study could be a guide for further studies with a larger cohort. They may help improve the results of the knee surgeries.

\section{Funding}

No financial biases exist for any author. No support in the form of grants, equipment, or other items received.

\section{References}

[1] Willcox, N.M., Clarke, J.V., Smith, B.R., Deakin, A.H. and Deep, K. (2012) A Comparison of Radiological and Computer Navigation Measurements of Lower Limb Coronal Alignment before and after Total Knee Replacement. The Bone \& Joint Journal, 94, 1234-1240. http://dx.doi.org/10.1302/0301-620X.94B9.28250

[2] Hsu, R.W., Himeno, S., Coventry, M.B. and Chao, E.Y. (1990) Normal Axial Alignment of the Lower Extremity and Load-Bearing Distribution at the Knee. Clinical Orthopaedics and Related Research, 255, 215-227.

[3] Tang, W.M., Zhu, Y.H. and Chiu, K.Y. (2000) Axial Alignment of the Lower Extremity in Chinese Adults. The Journal of Bone and Joint Surgery (American Volume), 82, 1603-1608.

[4] Igbigbi, P.S., Msamati, B.C. and Matanje, B. (2003) Normal Axial Angles of the Knee Joint in Adult İndigenous Malawians. East African Medical Journal, 80, 415-418.

[5] Moreland, J.R., Bassett, L.W. and Hanker, G.J. (1987) Radiographic Analysis of the Axial Alignment of the Lower Extremity. The Journal of Bone and Joint Surgery (American Volume), 69, 745-749.

[6] Ritter, M.A., Faris, P.M., Keating, E.M. and Meding, J.B. (1994) Postoperative Alignment of Total Knee Replacement. Its Effect on Survival. Clinical Orthopaedics and Related Research, 299, 153-156.

[7] Khattak, M.J., Umer, M., Davis, E.T., Habib, M. and Ahmed, M. (2010) Lower-Limb Alignment and Posterior Tibial Slope in Pakistanis: A Radiographic Study. Journal of Orthopaedic Surgery, 18, 22-25.

[8] Sharma, L., Song, J., Felson, D.T., Cahue, S., Shamiyeh, E. And Dunlop, D.D. (2001) The Role of Knee Alignment in Disease Progression and Functional Decline in Knee Osteoarthritis. The Journal of the American Medical Association, 286, 188-195. http://dx.doi.org/10.1001/jama.286.2.188

[9] Catani, F., Leardini, A., Ensini, A., Cucca, G., Bragonzoni, L., Toksvig-Larsen, S., et al. (2004) The Stability of the Cemented Tibial Component of Total Knee Arthroplasty: Posterior Cruciate-Retaining versus Posterior-Stabilized Design. The Journal of Arthroplasty, 19, 775-782. http://dx.doi.org/10.1016/j.arth.2004.01.013

[10] Bellemans, J., Robijns, F., Duerinckx, J., Banks, S. and Vandenneucker, H. (2005) The İnfluence of Tibial Slope on Maximal Flexion after Total Knee Arthroplasty. Knee Surgery, Sports Traumatology, Arthroscopy, 13, $193-196$. http://dx.doi.org/10.1007/s00167-004-0557-x

[11] Ostermeier, S., Hurschler, C., Windhagen, H. And Stukenborg-Colsman, C. (2006) In Vitro Investigation of the Influence of Tibial Slope on Quadriceps Extension Force after Total Knee Arthroplasty. Knee Surgery, Sports Traumatology, Arthroscopy, 14, 934-939. http://dx.doi.org/10.1007/s00167-006-0078-x 